\title{
Effect of Silicon Carbide Particles in Explosive Cladded Aluminum Hybrid Composites
}

\author{
S. Saravanan ${ }^{1, a^{*}}$, K. Raghukandan ${ }^{2, b}$ and G. Murugan ${ }^{3, c}$ \\ ${ }^{1^{*}}$ Department of Mechanical Engineering, Annamalai University, Annamalainagar, India \\ ${ }^{2}$ Department of Manufacturing Engineering, Annamalai University, Annamalainagar, India \\ ${ }^{3}$ Department of Mechanical Engineering, Annamalai University, Annamalainagar, India \\ assvcdm@gmail.com, braghukandan@gmail.com, cgeeyemcdm@gmail.com
}

\section{Keywords: Explosive Cladding, Aluminum, Silicon Carbide, Microstructure, Hardness}

\begin{abstract}
In this study, explosive cladding of aluminum 5052-aluminum 1100 plates with silicon carbide particles spread between them is attempted. The percentage of silicon carbide particles is varied from $6 \%$ to $12 \%$ by wt., keeping other parameters viz., standoff distance, loading ratio, flyer and base plate thickness and preset angle as constant. The influence of silicon carbide $\left(\mathrm{SiC}_{\mathrm{p}}\right)$ on the interface microstructure and strength are discussed and correlated with the conventional explosive clad. The interface microstructure reveals a smooth interface free from defects and an increase in silicon carbide particles enhances the strength of the dissimilar aluminum explosive clad.
\end{abstract}

\section{Introduction}

Hybrid aluminium composites, having one or more reinforcements, are extensively employed in aerospace, marine, automotive and defence applications. Hybrid composites exhibit superior mechanical properties viz., higher hardness, fracture toughness, fatigue resistance and creep resistance [1]. In addition, these composites show higher corrosion and wear resistance and thereby, are excellent replacement for conventional metals and alloys [2]. The choice of processing condition, fabrication process and the choice of reinforcement significantly improve the mechanical and metallurgical properties of hybrid composites.

Various researchers prepared and analysed the metallurgical and mechanical properties of hybrid composites through powder metallurgy techniques. Few of the salient contributions are summarized here. Rana et al. prepared silicon carbide reinforced aluminium alloy composites by melt-stir casting assisted with ultrasonic vibrations [3]. They concluded that the ultrasonic vibration improves the grain refinement and promote uniform distribution of the reinforcements. Afkham et al. employed aluminium nano particles as reinforcement in the preparation of aluminium matrix composites and reported better mechanical properties [4]. In this context, Ma et al. recommended the usage of smaller grain sized reinforcements for attaining high wear and mechanical properties [5]. In another study, Dasari et al. examined the mechanical properties of liquid infiltrated aluminium alloys reinforced with graphene oxide and reduced graphene oxides [6]. Shirvanimoghaddam et al. studied the improvement in hardness and tensile strength of boron carbide, titanium diboride and zirconium silicate reinforced aluminium alloy composites [7]. Though significant research on hybrid aluminium composites was performed in powder metallurgy technique, studies on the preparation of silicon carbide reinforced dissimilar aluminium composites by explosive cladding is scarce. In this study, Al 5052 and Al 1100 aluminium plates are explosively cladded with varied percentage of silicon carbide particles spread on the base plate. The influence of silicon carbide on microstructure and mechanical strength of the dissimilar aluminium clad is reported. 


\section{Experimental}

A parallel explosive cladding configuration with silicon carbide particles placed at the base plate was attempted (Fig. 1). Silicon carbide particles of varied proportion (6-12 \%, by wt. of flyer plate) are dispersed in the mid region of the base plate (Al 1100), having dimension $80 \mathrm{~mm} \mathrm{X} 60 \mathrm{~mm}$ X 5 $\mathrm{mm}$. Al 5052 plate $(80 \mathrm{~mm} \mathrm{X} 60 \mathrm{~mm} \mathrm{X} 2 \mathrm{~mm}$ ) is positioned $5 \mathrm{~mm}$ above the base plate (standoff distance).The chemical composition of parent metals are given in Table 1. Commercial chemical explosive (detonation velocity-4000 m/s, density-1.2 g/ $\mathrm{cm}^{3}$ ) was packed above the flyer plate at a constant loading ratio, $\mathrm{R}$ of 0.8 , and the detonator was positioned on one corner of the explosive pack. The experimental conditions were fixed based on the trial experiments.

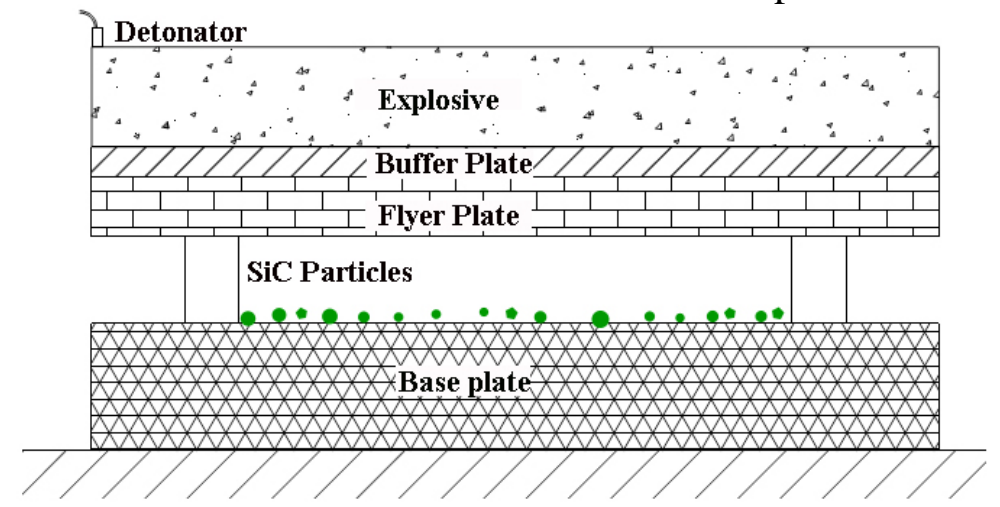

Fig.1 Explosive cladding with silicon carbide particles

Table 1 Chemical composition of participant metals

\begin{tabular}{llllllllll}
\hline Material & \multicolumn{10}{c}{ Composition (wt. \%) } \\
\hline & $\mathrm{Cu}$ & $\mathrm{Mn}$ & $\mathrm{Si}$ & $\mathrm{Mg}$ & $\mathrm{Zn}$ & $\mathrm{Fe}$ & $\mathrm{Cr}$ & $\mathrm{Ti}$ & $\mathrm{Al}$ \\
\hline $\mathrm{Al} 1100$ & 0.0292 & 0.0177 & 0.101 & 0.0169 & 0.0158 & 0.479 & - & - & Bal \\
\hline $\mathrm{Al} 5052$ & 0.1 & 0.4 & 0.4 & 4.2 & 0.25 & 0.4 & 0.15 & 0.15 & Bal \\
\hline
\end{tabular}

Post cladding, the specimens for metallographic observations were sectioned parallel to the detonation direction, following standard metallurgical procedures viz., grinding, polishing and etching (Kellers reagent-5 ml HF, $10 \mathrm{ml} \mathrm{H}_{2} \mathrm{SO}_{4}, 85 \mathrm{ml} \mathrm{H}_{2} \mathrm{O}$ for $20 \mathrm{~s}$ ). The post cladding metallographic analysis was performed in a VERSAMAT-3 optical microscope equipped with Clemex image analyzing system. Vickers micro-hardness measurement across the explosive clads were conducted on a ZWICK micro-hardness tester applying $100 \mathrm{~g}$ load (ASTM E 384 standard) and the results are presented.

\section{Results and discussion}

Microstructure. The interface microstructure of the SiCp dispersed hybrid aluminum explosive clad are shown in Fig. 2(a-d). The interface exhibit a smooth interface free from jet trapping or formation of any reaction compounds. The interfaces reveal the dispersion of silicon carbide particles (SiCp), visible as a continuous black patch. The thickness of black region increases with the percentage of silicon carbide employed at the middle of the dissimilar aluminum clad interface. The silicon carbide particles, with reduced size, are distributed uniformly across the interface. The grains closer to the interface are smaller and oriented towards the direction of detonation. 

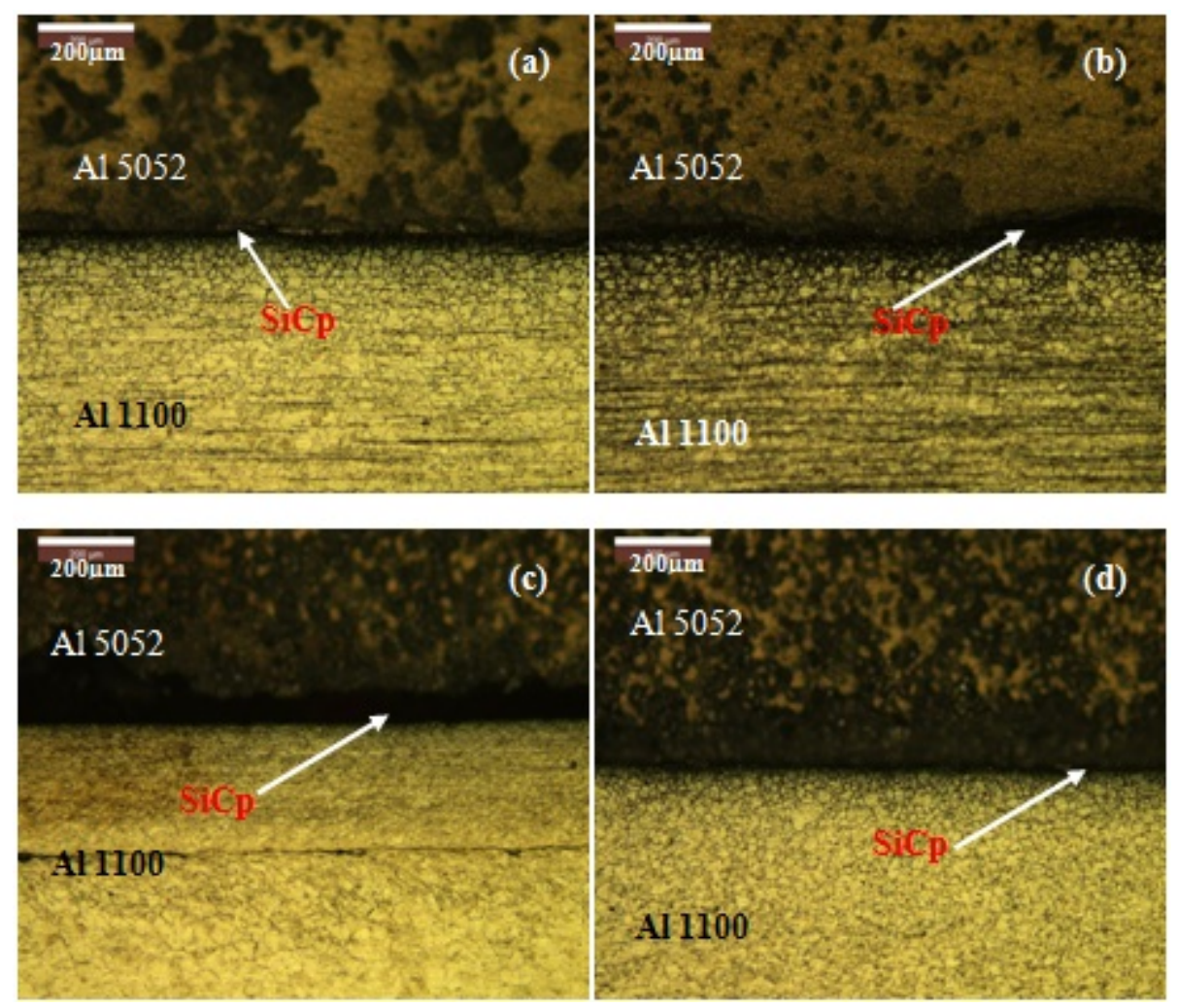

Fig. 2 Microstructure of the Al5052-Al 1100 explosive clad (a) $6 \% \operatorname{SiCp}($ b) $8 \% \operatorname{SiCp}(c) 10 \% \operatorname{SiCp}(d) 12 \% \operatorname{SiCp}$

The interface microstructure of dissimilar aluminium (Al 5052-Al 1100) explosive clad with 6\% of $\mathrm{SiCp}$ is shown in Fig. 2.a. It is observed that the silicon carbide particles are uniformly distributed across the interface. The interface exhibit a straight interface, free from trapping of escaping jet or formation of continuous molten interlayer. The thickness of silicon carbide particles at the interface is measured as $1.39 \mathrm{~mm}$. However, it increases to $1.48 \mathrm{~mm}$, when the quantity of silicon carbide is enhanced to 8 \% (Fig. 2.b). Formations of cluster or agglomerations of SiCp particles are not observed at the interface (Fig.2.b). The SiCp layer's thickness at the dissimilar aluminium clad interface further increases to $1.54 \mathrm{~mm}$, when the concentration reaches $10 \%$ (Fig.2.c). On the contrary, for a $12 \% \mathrm{SiCp}$ concentration, the micrographs (Fig. 2.d) reveal agglomeration and particle clusters of $\mathrm{Al}_{2} \mathrm{SiC}$, identified by $\mathrm{EDS}$ analysis. Formation of agglomeration or clusters is consistent with the reports of Dhas et al [8]. The concentration of silicon carbide particles at the interface holds a significant effect on the micro-hardness of the interface as well (detailed in the next section).

Hardness. The average of three Vickers micro-hardness measurements at equal intervals from the cross sections of silicon carbide reinforced dissimilar aluminum explosive clad is shown in Fig.3. Post clad hardness of both aluminum grades are higher than the pre clad conditions (Al 1100- 47 $\mathrm{Hv}, \mathrm{Al} 5052-74 \mathrm{Hv}$ ) following high pressure and the cold deformation experienced during the high impact collision. This is consistent with the earlier reports of Saravanan et al [9-11]. There is no significant variation in the hardness at the hardness of silicon carbide particles.

\section{Conclusions}

The present study reports the influence of varied percentage of silicon carbide on the microstructure and micro-hardness of Al 5052-SiCp-Al 1100 explosive clads. The following salient conclusions are drawn from this experimental study: 
1. The introduction of silicon carbide as reinforcement in aluminium composites significantly improves the strength characteristics.

2. The Al 5052-SiCp-Al 1100 explosive clad with $10 \%$ silicon carbide exhibit better strength.

3. As the concentration of silicon carbide particles enhances its thickness on the interface increases as well.

4. The enhancement in the mechanical properties of silicon carbide reinforced dissimilar aluminium explosive clads promises to be a potential candidate for marine and offshore structural applications

\section{References}

[1] T. Rajmohan, T.K. Palanikumar, S. Ranganathan, Evaluation of mechanical and wear properties of hybrid aluminium matrix composites. T.Nonferr. Metal. Soc. 23(9) (2013) 25092517. https://doi.org/10.1016/s1003-6326(13)62762-4

[2] S. Saravanan, K.Raghukandan, P. Kumar, Effect of wire mesh interlayer in explosive cladding of dissimilar grade aluminum plates, J.Cent. South Univ, 26 (3) (2019) 604-611. https://doi.org/10.1007/s11771-019-4031-9

[3] R.S. Rana, R. Purohit, V.K. Soni, S. Das, Characterization of mechanical properties and microstructure of aluminium alloy-SiC composites. Mater. Today 2(4-5), (2015)1149-1156. https://doi.org/10.1016/j.matpr.2015.07.026

[4] Y. Afkham, R.A.Khosroshahi, S.Rahimpour, C.Aavani, D.Brabazon, R.T.Mousavian, Enhanced mechanical properties of in situ aluminium matrix composites reinforced by alumina nanoparticles. Arch. Civil Mech. Engg, 18(1), (2018) 215-226. https://doi.org/10.1016/j.acme.2017.06.011

[5] S.Ma, E.Xu, Z.Zhu, Q. Liu, S.Yu, J.Liu, H.Zhong, Y. Jiang, Mechanical and wear performances of aluminum/sintered-carbon composites produced by pressure infiltration for $\begin{array}{llll}\text { pantograph sliders. Powder } & \text { Technol. } 326 \quad \text { 54-61. }\end{array}$ https://doi.org/10.1016/j.powtec.2017.12.027

[6] B.L.Dasari, M. Morshed, J.M.Nouri, D. Brabazon, S.Naher, Mechanical properties of graphene oxide reinforced aluminium matrix composites. Compos Part B: Eng, 145 (2018)136-144. https://doi.org/10.1016/j.compositesb.2018.03.022

[7] K. Shirvanimoghaddam, H.Khayyam, H.Abdizadeh, M.K.Akbari, A.H. Pakseresht, F. Abdi, A. Abbasi, M. Naebe, Effect of $\mathrm{B}_{4} \mathrm{C}, \mathrm{TiB}_{2}$ and $\mathrm{ZrSiO}_{4}$ ceramic particles on mechanical properties of aluminium matrix composites: Experimental investigation and predictive modelling. Ceram. Int., 42(5) 2016, 6206-6220. https://doi.org/10.1016/j.ceramint.2015.12.181

[8] D.E.J. Dhas, C. Velmurugan, K.L.D.Wins, K.P.BoopathiRaja, Effect of tungsten carbide, silicon carbide and graphite particulates on the mechanical and microstructural characteristics of AA 5052 hybrid composites. Ceram. Int. 45(1), (2019) 614-621. https://doi.org/10.1016/j.ceramint.2018.09.216

[9] S. Saravanan, K.Raghukandan, K.Hokamoto, Improved microstructure and mechanical properties of dissimilar explosive cladding by means of interlayer technique. Arch.Civil Mech. Engg. 16(4) (2016) 563-568. https://doi.org/10.1016/j.acme.2016.03.009

[10] S. Saravanan, K.Raghukandan, Diffusion kinetics in explosive cladding of dissimilar alloys as described through the Miedema model. Arch. Metall. Mater. 59(4) (2014) 1615-1618. https://doi.org/10.2478/amm-2014-0274

[11] S. Somasundaram, R.Krishnamurthy, H.Kazuyuki, 2017. Effect of process parameters on microstructural and mechanical properties of Ti- SS 304L explosive cladding. J. Cent. South Univ. 24(6) (2017) 1245-1251. https://doi.org/10.1007/s11771-017-3528-3 